\title{
Is London overbedded?
}

\author{
Brian Jarman
}

\begin{abstract}
Objective-To examine whether there are too many hospital beds in London.

Design-Analysis of data from the Hospital InPatient Enquiry, Mental Health Enquiry, health service indicators, and Emergency Bed Service.

Setting-England, London, and inner London.

Results-Hospital admission rates for acute plus geriatric services for London residents were very similar to the national values in all age groups. In the special case considered in the Tomlinson reportacute services in inner London-the admission rate was $22 \%$ above the value for England. However, the admission rate of inner deprived Londoners was $9 \%$ below that of comparable areas outside London. For psychiatry, admission rates in London roughly equalled those in comparable areas. When special health authorities were excluded, in 1990-1 there were $4 \%$ more acute plus geriatric beds available per resident in London than in England. Bed provision has been reduced more rapidly in London than nationally. Extrapolating the trend of bed closures forward indicates that beds (all and acute) per resident in London are now at about the national average. Data from the Emergency Bed Service indicate that the pressure on available hospital beds in London has been increasing since 1985.

Conclusions-Data regarding bed provision and utilisation for all specialties by London residents do not provide a case for reducing the total hospital bed stock in London at a rate faster than elsewhere. Bed closures should take account of London's relatively poorer social and primary health care circumstances, longer hospital waiting lists, poorer provision of residential homes, and evidence from the Emergency Bed Service of increasing pressure on beds. Higher average costs in London, some unavoidable, are forcing hospital beds to be closed at a faster rate in London than nationally.
\end{abstract}

\section{Introduction}

The King's Fund report on health care in London, the Tomlinson report, and the government's response to the Tomlinson report have suggested the closure of several hospitals in London..$^{1-3}$ Pressure for the closure of hospitals comes from three sources: the claim that Londoners use more hospital services than they should; demands for improved efficiency, resulting in a higher caseload per bed and therefore a reduced bed requirement; and the impact of market forces, resulting in fewer patients being referred to London from outside. This paper examines the validity of each of these to determine their possible impact.

Practice, St Mary's

Hospital Medical School, Lisson Grove Health Centre, London NW8 8EG

Brian Jarman, professor of general practice

\section{Method}

London is defined as the district health authorities used by the King's Fund reports ${ }^{14}$ and the Tomlinson report. ${ }^{2}$ This coincides with the Office of Population Censuses and Survey's definition of inner plus outer
London - the old Greater London Council areaexcept that the districts of Barking, Havering and Brentwood, Kingston and Esher, and Hounslow and Spelthorne include areas outside this area.

Hospital admission rates by age group were calculated for acute services, geriatric services, and for acute plus geriatric services (that is, all hospital services excluding psychiatric and maternity services) for the residents of inner London, the whole of London, and England as a whole for 1985-6, using data from the Hospital In-Patient Enquiry. ${ }^{5}$ Special health authorities' data were included in the analyses. Specialties were classified according to the specialty of the consultant in charge of the patient at the time of discharge. SH3 data on head counts of patients in hospital were used to provide an independent check of the data from the Hospital In-Patient Enquiry and were found to differ by only about $1 \%$ per district, on average.

Hospital In-Patient Enquiry data were not recorded after 1986, so more recent data were obtained from the Department of Health regarding acute plus geriatric hospitalisation rates, in terms of consultant episodes per resident, for 1990-1 (S Boyle, personal communication). ${ }^{6}$ For these, the figures for London were divided into high status areas, urban areas, and inner deprived areas and these were compared with areas outside London having similar social characteristics. ${ }^{4}$ The districts in inner deprived London are Bloomsbury and Islington, Camberwell, City and Hackney, Hampstead, Haringey, Lewisham and North Southwark, Newham, Parkside, Riverside, Tower Hamlets, Wandsworth, and West Lambeth. ${ }^{4}$

The availability of hospital beds for all specialties, (acute, geriatric, mental illness, mental handicap, and maternity), including and excluding special health authorities, was calculated from Department of Health data $^{6}$ for inner London, the whole of London, and England. Data on the flows of patients between areas were collected for 1985-65 and 1989-90 (S Boyle, personal communication)

For psychiatry services, data from the mental health enquiry ${ }^{7}$ for 1986 were used. The admission rates for all psychiatric services, excluding mental handicap and senile dementia, for London were compared with the rates and numbers expected based on, firstly, the national admission rates for England broken down by age, sex, and marital status and, secondly, the admission rates expected based on a model that allows for the influence of health and social factors on psychiatric admission rates. ${ }^{8}$ The figures for inner London and the whole of London were compared with those for England as a whole.

To estimate the pressure on available hospital beds in London, data were extracted from the Emergency Bed Service caseload report covering 1979 to $1991 .^{\circ}$

\section{Results}

The hospital admission rates of London residents for acute services, geriatric services, and acute plus 
FIG 1-Hospital admissions (acute plus geriatric) in England and London, 1985-6. Source: Hospital In-Patient Enquiry, $1986^{5}$

FIG 2-Acute hospital admissions and geriatric hospital admissions in England and London, 1985-6. Source: Hospital In-Patient Enquiry, 1986

FIG 3-Acute hospital admissions in England and inner London, 1985-6. Source: Hospital In-Patient Enquiry, 1986

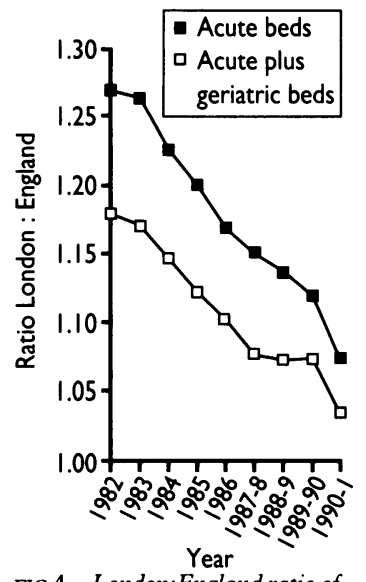

FIG 4 - London:England ratio of beds per resident
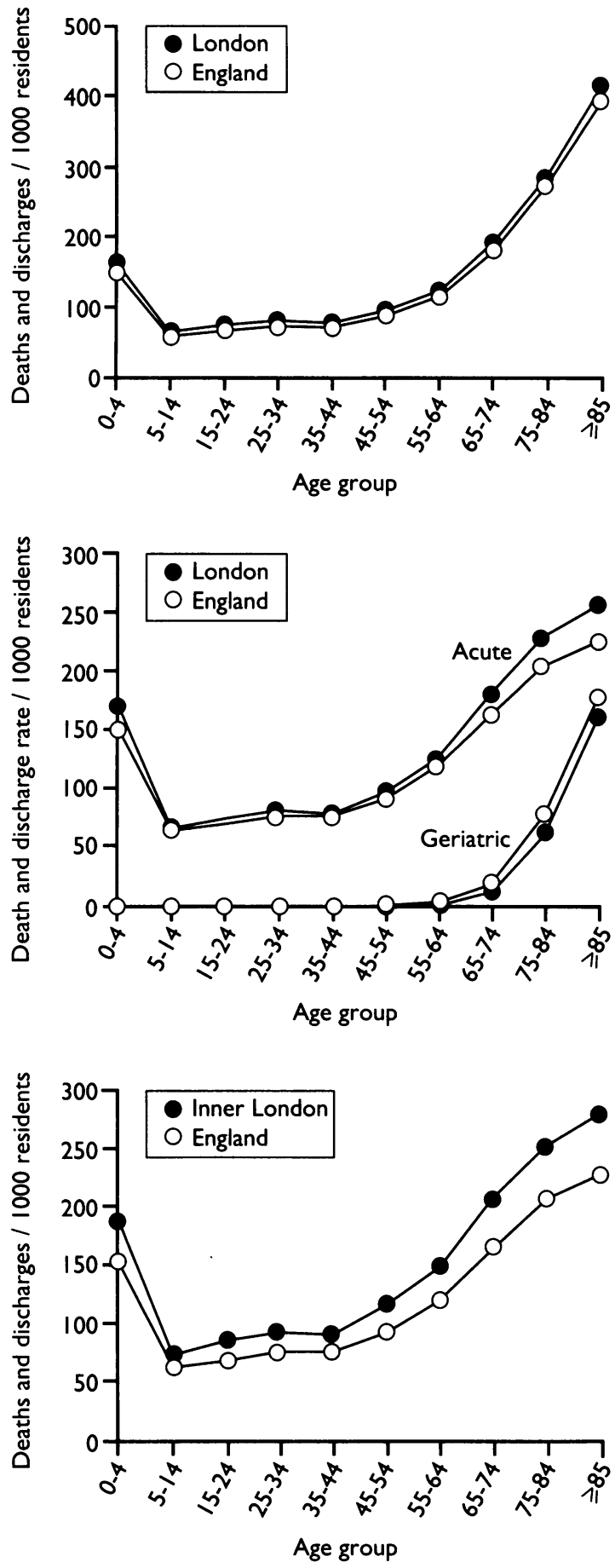

geriatric services in 1985-6 for the whole of London, inner London, and England are shown in figures 1-3. Figure 1 shows that the hospital admission rate of the residents of London for acute plus geriatric services is similar to that for the whole of England at each age group. The overall admission rate in London was 5\% above that of the residents of England. Standardisation for differences in the age composition of England and London makes only $0 \cdot 2 \%$ difference to the results. Figure 2 shows that for acute services London had higher admission rates throughout the age groups, whereas for geriatric services the London rates were lower than England rates. (One explanation for these differences would be that the type of elderly patients who were treated by acute specialists in London were under the care of geriatricians outside London.) If only acute admissions are examined only for inner London (the special case considered by Tomlinson) then the acute admission rate in inner London is found to be $22 \%$ above the rate for England (fig 3).

The admission rate for acute plus geriatric services
TABLE I-Hospitalisation rate 1990-1 in London and outside London. Figures are consultant episodes per 1000 residents, inpatients and dav cases, acute and geriatric ${ }^{\star}$ specialties combined

\begin{tabular}{lccc}
\hline & London & Non-London & $\begin{array}{c}\text { Ratio of } \\
\text { London:non-London }\end{array}$ \\
\hline Inner deprived area & 146.7 & 161.6 & 0.91 \\
Urban & 134.2 & 145.9 & 0.92 \\
High status area & 130.9 & 123.9 & 1.06 \\
Weighted total & $137.5 \dagger$ & 141.8 & 0.97 \\
\hline
\end{tabular}

*Geriatric specialty includes both finished and unfinished consultant episodes.

$\dagger 134 \cdot 8$ cases $/ 1000$ residents in England as a whole.

for 1990-1 (table I) was only $2 \%$ higher in London than in England. ${ }^{5}$ However, the figures for 1990-1 given in this table also indicate that the admission rate in inner deprived London is about $9 \%$ below that of comparable areas ${ }^{4}$ outside London such as Liverpool or Manchester.

In 1982, excluding the special health authorities, there were $27 \%$ more acute beds available in London per resident than the average in England; by 1990-1 this had reduced to $7 \%$. In the case of inner London in 1990-1 there were 54\% more, and in outer London $19 \%$ fewer, acute beds per resident than the national average. When the availability of acute plus geriatric beds is considered London had $18 \%$ more beds per resident in 1982 but this had reduced to only $4 \%$ more in 1990-1 (37\% more in inner London, $15 \%$ fewer in outer London). If all beds are considered (acute, geriatric, mental illness, mental handicap, and maternity) then London had 5\% more beds per head in 1990-1 than England. If the special health authority beds are included, in 1990-1 London had 9\% more beds per person than England.

Figure 4 shows that the rate of reduction of acute beds per resident has been more rapid in London than in England over the past 10 years. If the data are extrapolated to 1993, the ratios for acute beds and for all beds in London and England are seen to be about equal. This indicates that, excluding the special health authorities, with the current rate of closures the level of hospital bed provision in London is even now likely to be about the national level. If special health authorities (which are national referral centres, only $61 \%$ of whose patients come from London) are included with the London beds, then bed provision in London is about $5 \%$ above the values given above. The bed closures are part of a national trend of hospital bed reductions that has been happening over the past 40 years (and especially since 1970) whereby the increase in hospital admissions has been more than compensated by the reduction in lengths of stay, thereby resulting in reduced bed use and availability (fig 5).$^{10} \mathrm{NHS}$ hospitals are "treating more and more people," but in fewer and fewer beds with shorter and shorter lengths of stay.

Examination of the data on patient flows for acute services in $1989-90$ showed that $11 \%$ of the acute patients treated in London are non-residents. In inner deprived London $35 \%$ of patients treated are from outside of the area, although over $60 \%$ of these are from other areas of London. The patient flows for acute plus geriatric services for $1985-6$ show that $90 \%$ of the patients treated in London hospitals (in London district health authorities, excluding special health authority hospitals) are London residents. Conversely, $91 \%$ of London residents are treated in London district health authority hospitals, $6 \%$ in London special health authority hospitals, and 3\% outside London.

Table II gives the results for psychiatry services. These show that the admission rate for London is $2 \%$ above the value predicted, based on a model that takes into account health status and social factors. ${ }^{8}$ The psychiatric admission rate for London is $8 \%$ above the value expected by applying the national admission 


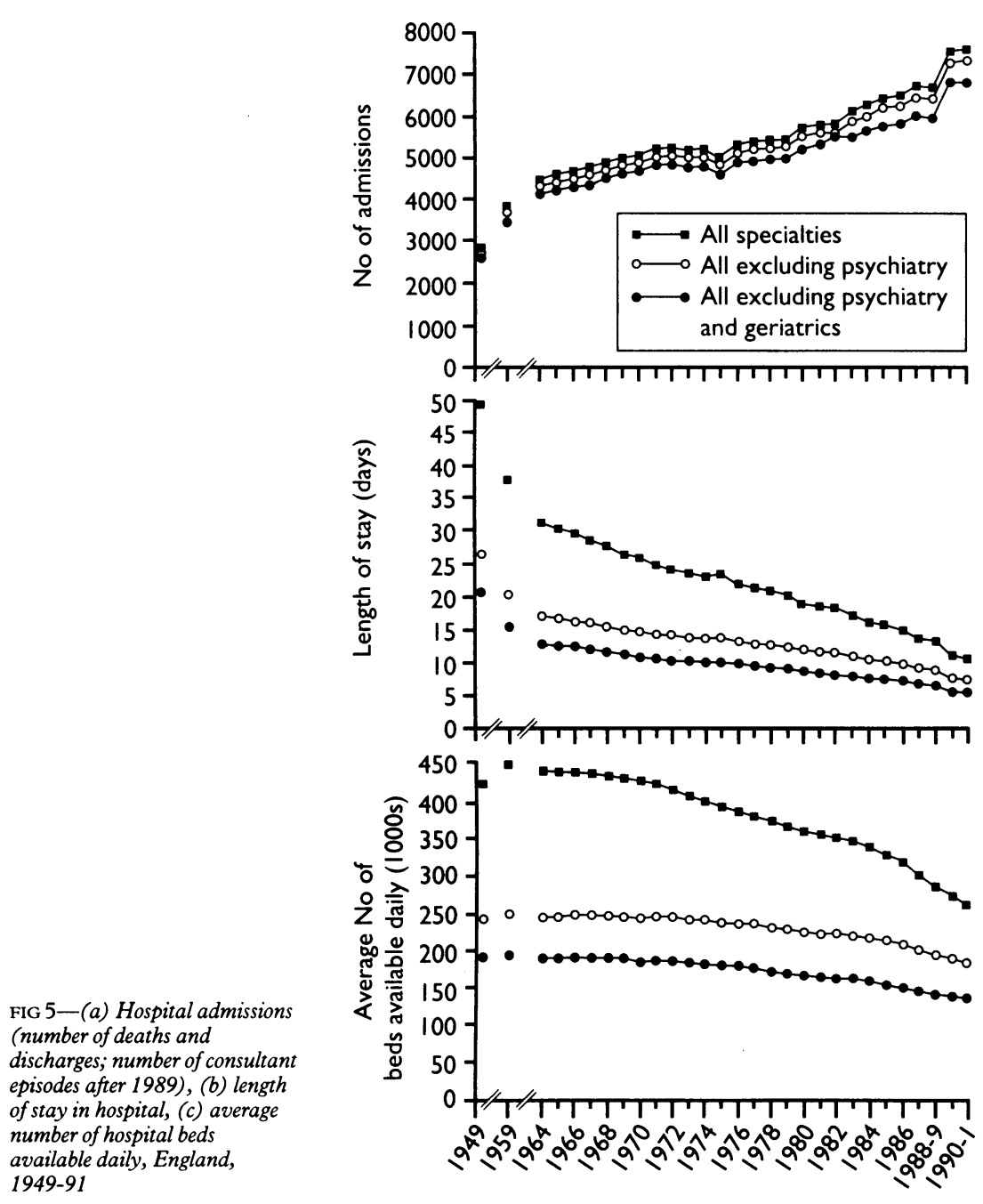

rates for each age, sex, and marital status group to the age, sex, and marital status structure of the population of London.

Figure 6 shows the number of applications to use the Emergency Bed Service that were medically refereed. The service, which was set up by the King's Fund in 1938 and became part of the NHS in 1978, is for use by general practitioners when they have difficulty finding a hospital bed to which they can admit a patient. The total number of cases reduced between 1987 and 1991 from 30726 to 22391 but the number of cases that had to be medically refereed, because of difficulties finding a bed, increased and their proportion of the total has increased from $8 \%$ in 1979 to $33 \%$ in 1991 . The total number of medically refereed cases stayed fairly constant from 1979 to 1984 but increased threefold between 1984 and 1991. The total applications to use the service are determined mainly by general practitioners, and the reduction from 1987 to 1991 may reflect the fact that there have been some improvements in primary care in London, with a lower proportion of single handed general practitioners. ${ }^{13}$ However, the proportion of cases that are medically refereed "reflects the level of pressure on available hospital beds." The total caseload has shown a reduction, "the referral rate,

refereed applications to Emergency Bed Service, 1979-91 however, continues its seemingly remorseless rise." These data suggest that the pressure on available hospital beds in London has considerably increased since 1985.

\section{Discussion}

THE TOMLINSON RECOMMENDATIONS

In October 1991 Professor Tomlinson and his committee were asked "To advise the Secretaries of State for Health and Education and Science on how the relevant statutory authorities are addressing the provision of health care in inner London . . . taking account of . . . future developments in the provision of acute and primary care." They were asked to concentrate on acute services in inner London; they were not asked to examine all hospital services (acute, geriatric, psychiatric, and maternity) in the whole of London. They noted that inner Londoners make greater use, and have greater availability, of acute services than the national average. They made several recommendations regarding bed closures in London. But these recommendations for bed closures, based on a report that considered acute services in inner London, will also affect hospital beds other than acute beds (because when hospitals close, geriatric and other non-acute beds are usually lost as well as acute beds) and patients in the whole of London (because outer Londoners use inner London beds).

The results of the present study confirm that the acute hospitalisation rate of the residents of inner London was indeed $22 \%$ above that of England in 1985-6. However, it is also shown that the hospitalisation rate for acute plus geriatric services of the residents of the whole of London was only $5 \%$ (in 1985$6 ; 2 \%$ in 1990-1) above that of England. In addition, when inner London is compared with similar areas outside London the residents of inner London use acute hospital services at a rate that is $9 \%$ below that of comparable areas with similar social conditions, such as Liverpool and Manchester. Hence, hospital use does not indicate a need to reduce the total acute plus geriatric bed capacity in London, judging by national norms. The same conclusion holds for psychiatric services.

AVAILABILITY OF HOSPITAL BEDS AND RESIDENTIAI HOME PLACES

Excluding the special health authorities, in 1990-1 London had $4 \%$ more acute plus geriatric beds available per resident than England, and this had reduced from $18 \%$ more in 1982. Two factors must, however, be considered. Firstly, the distribution of acute plus geriatric beds per head within London is uneven, with inner London districts having $37 \%$ more than the national average and outer London $15 \%$ less in 1990-1. (Of the four Thames regions, North West Thames has the lowest supply of acute plus geriatric beds (the supply of acute beds is $20 \%$ below the value for England and is the lowest in the country) and North East Thames the highest.) Secondly, the availability of beds in London is similar to that in comparable districts elsewhere in the country. Hence, if there should be a reduction in the quantity of beds in London, this conclusion does not apply across the whole of the capital. Also, if London is considered to be overbedded, then the same applies to other inner city areas.

A further factor to be considered in relation to availability of geriatric beds is the provision of residential home places for elderly people. The data show that residential accommodation for elderly people (local authority, voluntary, and private homes) is lower in London than nationally $(20.5$ places per 1000 aged 65 and over in inner London, and 23.1 in outer London

168657

^Based on national age, sex, marital status admission rates and age, sex, marital status structures of areas studied. $\nmid$ Based on predictive model used. 
compared with 31.6 in England in 1991).'2 Furthermore, the number of places in residential homes has fallen by a fifth over the past five years in inner London but has increased nationally by $11 \%$. There are now $54 \%$ more residents aged 65 or more in residential homes for the elderly per 1000 elderly people in England than in London. The figures for residential home occupancy also reflect those for their availability. ${ }^{12}$

\section{BED CLOSURES FORCED BY THE INTERNAL MARKET}

Pressure rises from the working of the internal market in health services introduced in April 1991. This study found that about $10 \%$ of acute plus geriatric hospital admissions in London are devoted to the care of non-Londoners. The higher costs in London hospitals are leading to a withdrawal of these referrals and hence a fall in the demand for acute inpatient services in London. ${ }^{12}$

Again a note of caution must be introduced. Although this is true of London as a whole, there is a dichotomy between the inner London hospitals, which are providing expensive care not just to non-Londoners but also to residents of the outer London districts, and outer London hospitals, which currently do not produce enough episodes of care to satisfy the needs of their own residents. Moreover, London has a concentration of regional specialty services (especially in the special health authorities) and it may be considered appropriate that these should continue to be sited in the capital and that a small percentage of patients should continue to come from outside London for these services.

\section{GEOGRAPHICAL DISTRIBUTION OF BEDS IN LONDON}

The distribution of hospital services that has developed in London over the years may seem inappropriate for the requirements of the present residents because the services are concentrated too much in inner London. However, in planning hospital services for Londoners account must be taken of the current geographical distribution of beds: although not ideal, it does fit in with the transport system in London, which is much better when travelling radially to or from the centre than when travelling across town. It may not be practicable to relocate hospitals from the centre of London in the short term, but any long term plan for London must take account of the geographical distribution of London hospital beds.

\section{TOO MANY HIGH TECH BEDS}

There are too many high tech acute beds and too few low tech beds for elderly people. If beds for low technology services were to be provided in community centres, as suggested by the King's Fund Commission' and the Tomlinson report, ${ }^{2}$ these should be available before the closure of acute beds. However, it is first necessary to evaluate how effectively community centre beds compensate for acute hospital beds. In the shorter term it may be more practical to redesignate hospital bed usage more towards the care of elderly people and less towards acute hospital services. Furthermore, it should be noted that additional pressure on beds for elderly people is likely to arise as a result of the relatively lower provision, and continuing reduction, of residential home places for elderly people in London.

THROUGHPUT IN LONDON IS AT ABOUT NATIONAL LEVEL

It has been shown that when throughput rates for acute specialties in London are compared with those nationally, London has a throughput rate in the acute specialties that is only 4\% less than that of England; in the case of inner deprived London the difference is just $2 \%{ }^{4}$ This suggests that London is only marginally less efficient than the national average. It would be inappropriate, without some firm evidence as to how it might come about, to assume, as Tomlinson does, that London might obtain throughput levels as much as $50 \%$ higher than they are currently. Moreover, the underdevelopment of the primary and community health care system in London" acts as a constraint on the ability of London's hospitals to achieve national throughput targets. The King's Fund, the Tomlinson reports, and the government's response have all recognised the crucial need for investment in the primary care infrastructure. Considerations of relative efficiency would not seem a strong foundation for the argument that London is overbedded.

BED PROVISION SHOULD TAKE ACCOUNT OF NEEDS AND COSTS IN LONDON

Further research is required in order to establish the appropriate level of resource allocation both to and within London, taking account not just of the relative health care needs and social conditions of Londoners but also of the high cost environment in London and the special teaching and research responsibilities of some of London's hospitals.

The one factor truly militating against the current level of bed capacity in London seems to be the working of the internal market. Purchasers from outside of London, and indeed within London, are looking to place contracts with provider hospitals that give value for money. In this environment it is difficult to see inner city London hospitals competing successfully. However, this is partly because of the unavoidable higher costs of providing hospital services in the capital city.

It is clear that neither hospital use by London residents, nor the availability of hospital beds, nor considerations of relative efficiency provide a case for a reduction of the total bed capacity in London. The long term basis of change should be towards a realignment of provision both geographically, from inner to outer London, and from acute specialties towards care for elderly people. It is important that any changes should be considered in the context of London's transport system and the particular problems in primary care ${ }^{11}$ and social services, ${ }^{13}$ relatively longer hospital waiting lists, ${ }^{2}$ below average availability of places in residential homes, ${ }^{12}$ and the increasing pressure on available hospital beds. ${ }^{9}$

I am very grateful to Sean Boyle of the King's Fund and to Pat Davies for providing data and help with the writing of this paper, and also to Madhavi Bajekal, Susan Dolan, Debbie Hart, Tom Snow, and Nick Bosanquet for data analysis and comments. Any opinions expressed are my own.

1 King's Fund Commission on the Future of London's Acute Health Services. London health care 2010. London: King's Fund, 1992.

2 Tomlinson B. Report of the inquiry into London's health service, medical educatio and research. London: HMSO, 1992.

3 Department of Health. Making London better. Manchester: Health Publication Unit, 1993.

4 Boyle S, Smaje C. Acute health services in London: an analysis. London: King's Fund, 1992.

5 Office of Population Censuses and Surveys. Hospital in-patient enquin. London: HMSO, 1985.

6 Department of Health, Statistics Division. Summary of available beds. London: Department of Health, 1992.

Department of Health and Social Security. In-patient statistics from the mental health enquiry for England. London: HMSO, 1986.

8 Jarman $B$, Hirsch $S$, White $P$, Driscoll R. Predicting psychiatric admission

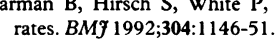

9 Emergency Bed Service. Caseload report. London: EBS, 1992

10 Department of Health. Health and personal social services statistics for England, 1992. London: HMSO, 1992 (and other years)

11 Jarman B, Bosanquet N. Primary health care in London-changes since the Acheson report. BMJ 1992;305:1130-3.

12 Government Statistical Service. Residential accommodation for elderly and for younger physically handicapped people: all residents in local authority voluntary and private homes year ending 31 March 1986 to year ending 31 March 1991. London: HMSO, 1992. (RA/86-91/2(H).)

13 Boyle S, Smaje C. Primary health services in London. London: King's Fund (in press).

(Accepted 16 March 1993) 